\title{
Ruptura completa del tendón del cuádriceps
}

\author{
Quadriceps tendon rupture \\ Itzel Ariadna Hernández Dehesa, * María de Guadalupe Gómez Pérez, ${ }^{\ddagger}$ Georgina Cornelio Rodríguez ${ }^{\S}$ \\ Citar como: Hernández DIA, Gómez PMG, Cornelio RG. Ruptura completa del tendón del cuádriceps. \\ Acta Med. 2021; 19 (1): 136-137. https://dx.doi.org/10.35366/98587
}

\begin{abstract}
Masculino de 45 años sufre traumatismo directo en tercio distal de la cara anterior del muslo izquierdo, valorado por médico ortopedista quien observó aumento de volumen acompañado de edema prepatelar, doloroso a la palpación, depresión a la palpación en la topografía del tendón del cuádriceps, dolor a la flexión pasiva y activa. El ultrasonido muestra pérdida del patrón fibrilar e interrupción de la mayor parte de las fibras del tendón del cuádriceps (Figura 1); en forma complementaria se decide solicitar estudio de resonancia magnética de rodilla donde existe ruptura completa del tendón del cuádriceps en su inserción y como signo indirecto, situación de rótula baja (Figuras 2A-C). Las lesiones del cuádriceps tienden a ser comunes entre atletas y adultos activos, desde contusiones musculares leves hasta la ruptura completa del tendón. El cuádriceps se compone del recto femoral, vasto lateral, vasto medial y vasto intermedio; éstos se insertan en la rótula como el tendón del
\end{abstract}

cuádriceps común. El tendón envuelve la rótula y se inserta en la tuberosidad tibial. ${ }^{1}$ La localización de la ruptura se demuestra que está a 1-2 cm de la parte superior del polo rotuliano, en la mayoría de los casos en la región avascular del tendón. ${ }^{2}$ La edad de presentación ocurre en adultos mayores de 50 años o atletas más jóvenes. ${ }^{3,4}$ El paciente puede experimentar sensación de desgarro en la rótula o «explosión» seguida de aumento de volumen y dificultad para soportar el peso. ${ }^{5}$ Es posible desarrollar hemartrosis aguda y sensibilidad focal por encima de la rótula, no se puede mantener la pierna recta ni levantar la pierna contra la gravedad mientras está en decúbito supino. ${ }^{4,6}$ Los hallazgos por imagen y las radiografías revelan fracturas por avulsión y rótula baja (medición Insall-Salvati), por ultrasonido se observa zona hipoecoica o anecoica, incremento en el grosor o disminución de la ecogenicidad. ${ }^{7}$ La resonancia magnética (mejor método) demuestra interrupción de la

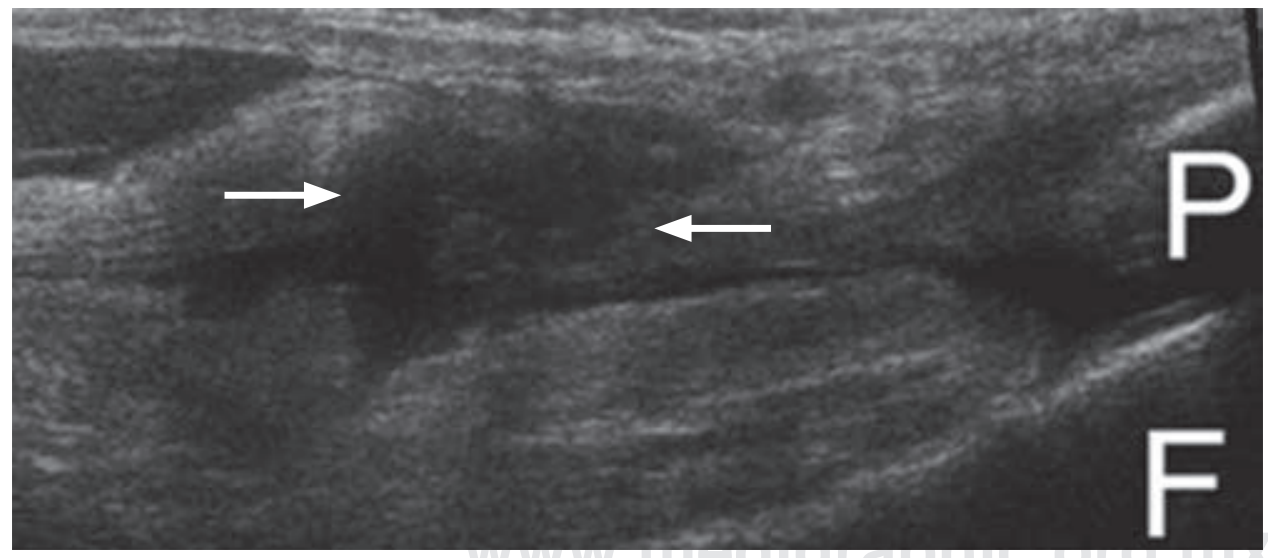

Figura 1:

Ultrasonido

musculoesquelético en modo B que muestra al tendón del cuádriceps izquierdo con interrupción y retracción de las fibras musculares (flechas blancas) así como a la patela (P) y la porción distal del fémur.

\footnotetext{
* Médico Radiólogo. Curso de Alta Especialidad en Resonancia Magnética Corporal. Facultad de Medicina de la UNAM. Hospital Ángeles Acoxpa.

* Médico Radiólogo. Profesora Titular del Curso de Alta Especialidad en Resonancia Magnética Corporal.

§ Médico Radiólogo. Hospital Ángeles Roma.
}

Hospital Ángeles Pedregal. CDMX, México.
Correspondencia:

Dra. Itzel Ariadna Hernández Dehesa

Correo electrónico: ariadnadehesahdez@hotmail.com

Aceptado: 25-03-2020.

www.medigraphic.com/actamedica

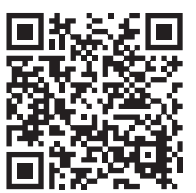



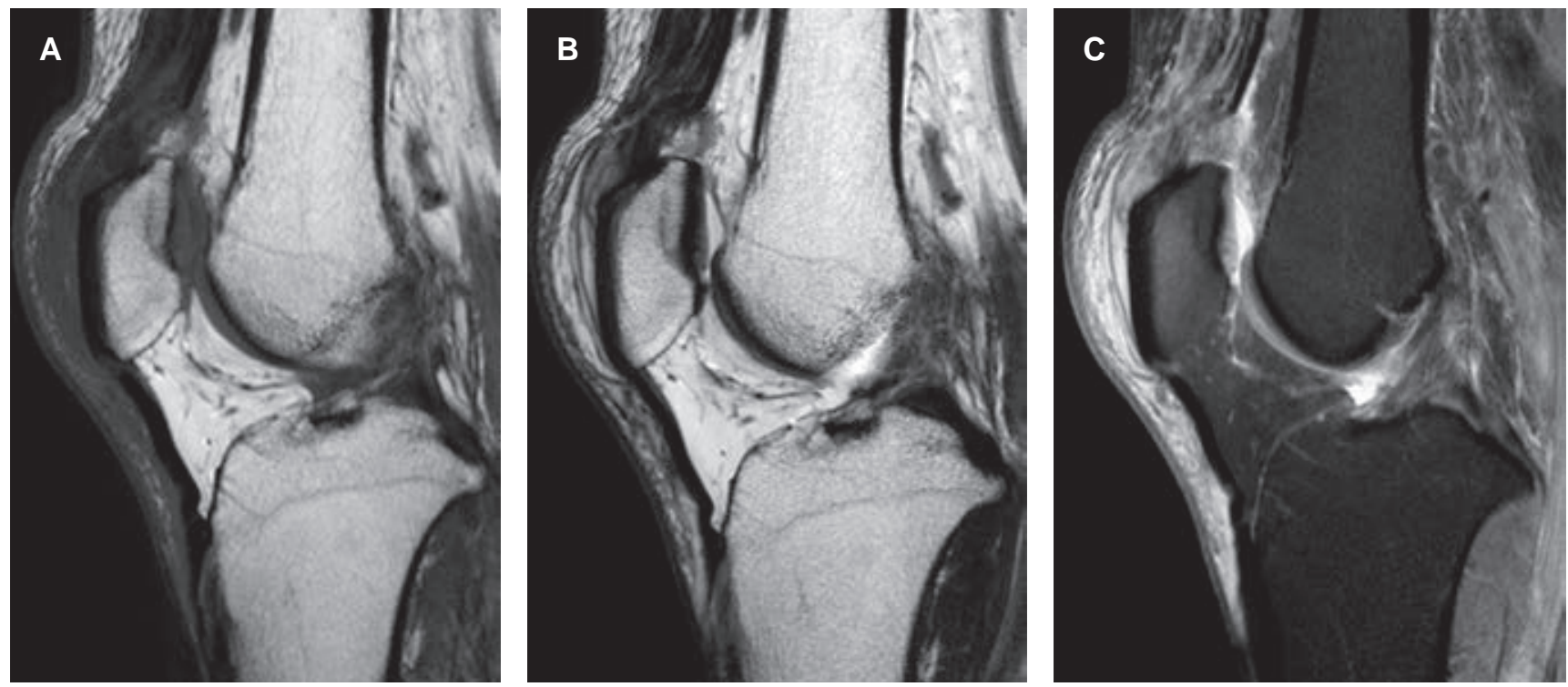

Figura 2: Resonancia magnética de rodilla izquierda, secuencias potenciadas en T1 (A), T2 (B) y FAT SAT (C), plano coronal. Tendón del cuádriceps con pérdida de tensión y dirección a nivel de su inserción patelar, irregularidad y pérdida de la mayor parte de sus fibras, las cuales incrementan su señal en T2; signos indirectos donde se observó ondulación de las fibras distales del tendón patelar a nivel de la inserción tibial y rótula de posición baja.

mayor parte de las fibras del tendón, como signo secundario el tendón rotuliano adquiere aspecto ondulado debido a la falta de tensión en extensión, ${ }^{4}$ también se demuestra derrame articular, edema de la medular ósea en la porción más superior de la rótula o edema intramuscular. ${ }^{4,5}$

\section{REFERENCIAS}

1. Modarresi S, Jude CM. Radiologic evaluation of the acutely painful knee in adults. EE. UU.: Biblioteca Nacional de Medicina; 2019. pp. 1-34.

2. Von Fange TJ. Quadriceps muscle and tendon injuries. EE. UU: Biblioteca Nacional de Medicina; 2019, pp. 1-61.
3. Ramseier LE, Werner CM, Heinzelmann M. Quadriceps and patellar tendon rupture. Injury. 2006; 37 (6): 516-519.

4. Ni Fhoghlu C, Ellanti P, Moriarity A, McCarthy T. MRI features of a quadriceps tendon rupture. BMJ Case Rep. 2015; 2015: bcr2015209942.

5. Yablon CM, Pai D, Dong Q, Jacobson JA. Magnetic resonance imaging of the extensor mechanism. Magn Reson Imaging Clin N Am. 2014; 22 (4): 601-620.

6. Brossard P, Le Roux G, Vasse B; Orthopedics, Traumatology Society of Western France (SOO). Acute quadriceps tendon rupture repaired by suture anchors: Outcomes at 7 years' follow-up in 25 cases. Orthop Traumatol Surg Res. 2017; 103 (4): 597-601.

7. LaRocco BG, Zlupko G, Sierzenski P. Ultrasound diagnosis of quadriceps tendon rupture. J Emerg Med. 2008; 35 (3): 293-295. 